\title{
STRENGTH BASED ASSESSMENT PADA MAHASISWA BERWIRAUSAHA
}

\author{
OLEH: \\ SINDY HUSNUL YAQIEN ${ }^{1}$, SANTOSO TRI RAHARJO², ARIE SURYA GUTAMA ${ }^{3}$ \\ 1. Mahasiswa Program Studi Sarjana (S-1) Kesejahteraan Sosial Fakultas Ilmu Sosial dan Ilmu Politik Universitas Padjadjaran \\ 2. Pusat Studi Kewirausahaan Sosial, CSR dan Pengembangan Masyarakat Fakultas Ilmu Sosial dan Ilmu Politik Universitas \\ Padjadjaran \\ 3. Departemen Kesejahteraan Sosial Fakultas Ilmu Sosial dan Ilmu Politik Universitas Padjadjaran
}

Email:

(shyaqien@gmail.com, santoso.tri.raharjo@unpad.ac.id; arrie.gutama@unpad.ac.id)

\begin{abstract}
ABSTRAK
Data Badan Pusat Statistik (BPS), bahwa pada tahun 2013-2014 ada sekitar 53 PTN yang tersebar di Indonesia dengan jumlah mahasiswa total 341.315, dan PTS di Indonesia berjumlah kurang lebih 625 dengan jumlah mahasiswa 272.350. Selain kuliah, saat ini banyak mahasiswa yang berwirausaha untuk memenuhi kebutuhan ekonominya. Mereka berwirausaha seperti, usaha kuliner, fashion, alat elektronik, jasa desain grafis, dan lain-lain.

Semangat berwirausaha sejalan dengan program pemerintah, yakni Program Mahasiswa Wirausaha (PMW). Dana yang dikucurkan pemerintah mencapai 2 miliar untuk mahasiswa terpilih dalam proposal usaha. Dana tersebut guna memberikan dukungan dan pendampingan bisnis mahasiswa. Program Pemerintah itu sejalan dengan semangat Nawacita, yaitu meningkatkan produktivitas rakyat dan daya saing secara internasional, serta menumbuhkan kemandirian ekonomi dengan pemberatan sektor-sektor strategis ekonomi domestik. Berbagai program Pemerintah itu akan membuka peluang usaha masyarakat menciptakan lapangan pekerjaan di tanah air ini.

Disamping kesibukan dalam akademik, mahasiswa yang berwirausaha memiliki keunikan. Berbagai tantangan dan hambatan tidak sedikit yang harus diselesaikan. Melalui kekuatannya, banyak mahasiswa wirausaha yang bisa menyeimbangkan antara prestasi dan bisnis. Dengan menggunakan perspektif kekuatan, pekerja sosial dapat membantu individu agar individu tersebut tidak hanya fokus pada masalah. Perspektif ini tidak hanya melihat masalah sebagai fokus utama, melainkan melihat sumber-sumber yang tersedia di sekitar individu yang bisa dijadikan kekuatan untuk menggapai tujuan.
\end{abstract}

\section{Kata Kunci: Strength Based Assessment, Wirausaha, Mahasiswa}

\section{ABSTRACT}

Data of Central Bureau of Statistics (BPS), that in the year 2013-2014 there are about 53 PTN scattered in Indonesia with total students 341,315 , and PTS in Indonesia amounted to approximately 625 with the number of students 272,350 . In addition to lectures, currently many students who are entrepreneur to meet the needs of its economy. They are entrepreneurs like, culinary business, fashion, electronic equipment, graphic design services, and others.

The spirit of entrepreneurship is in line with the government program, the Student Entrepreneurial Program (PMW). Funds disbursed by the government reach 2 billion for selected students in business proposals. The fund is to provide student support and assistance. The 
Government's program is in line with Nawacita's spirit of improving people's productivity and international competitiveness, and fostering economic independence with the strategic sectors of the domestic economy. Various Government programs that will open a business opportunity to create jobs in this country. The spirit of entrepreneurship is in line with the government program, the Student Entrepreneurial Program (PMW). Funds disbursed by the government reach 2 billion for selected students in business proposals. The fund is to provide student support and assistance.

Keywords: Strength Based Assessment, Entrepreneur, Student

\section{Pendahuluan}

Ratio wirausaha Indonesia yang pada 2013/2014 lalu masih 1,67 persen kini berdasarkan data BPS sudah naik menjadi 3,1 persen. Berdasarkan data BPS 2016 dengan jumlah penduduk 252 juta, jumlah wirausaha non pertanian yang menetap mencapai 7,8 juta orang atau 3,1 persen. Dengan demikian tingkat kewirausahaan Indonesia telah melampaui 2 persen dari populasi penduduk, sebagai syarat minimal suatu masyarakat akan sejahtera. Ratio wirausaha sebesar 3,1 persen itu masih lebih rendah dibandingkan dengan negara lain seperti Malaysia 5 persen, China 10 persen, Singapura 7 persen, Jepang 11 persen maupun AS yang 12 persen.

Bertumbuhnya wirausaha tak lepas dari peran masyarakat bersama pemerintah yang terus mendorong, juga swasta dan kalangan mahasiswa atau kampus. Langkah pemerintah mendorong setiap universitas yang ada di seluruh Indonesia untuk menciptakan mahasiswa wirausaha guna mempercepat pertumbuhan wirausaha baru di negeri sendiri mendapat dukungan. Banyaknya perguruan tinggi, baik negeri dan swasta dengan ribuan jumlah mahasiswa akan mampu melahirkan wirausaha muda unggul.
Data Badan Pusat Statistik (BPS), bahwa pada tahun 2013-2014 ada sekitar 53 PTN yang tersebar di Indonesia dengan jumlah mahasiswa total 341.315, dan PTS di Indonesia berjumlah kurang lebih 625 dengan jumlah mahasiswa 272.350. Selain kuliah, saat ini banyak mahasiswa yang berwirausaha untuk memenuhi kebutuhan ekonominya. Mereka berwirausaha seperti, usaha kuliner, fashion, alat elektronik, jasa desain grafis, dan lain-lain.

Semangat berwirausaha sejalan dengan program pemerintah, yakni Program Mahasiswa Wirausaha (PMW). Dana yang dikucurkan pemerintah mencapai 2 miliar untuk mahasiswa terpilih dalam proposal usaha. Dana tersebut guna memberikan dukungan dan pendampingan bisnis mahasiswa. Program Pemerintah itu sejalan dengan semangat Nawacita, yaitu meningkatkan produktivitas rakyat dan daya saing secara internasional, serta menumbuhkan kemandirian ekonomi dengan pemberatan sektor-sektor strategis ekonomi domestik. Berbagai program Pemerintah itu akan membuka peluang usaha masyarakat menciptakan lapangan pekerjaan di tanah air ini.

Disamping kesibukan dalam akademik, mahasiswa yang berwirausaha memiliki 
keunikan. Berbagai tantangan dan hambatan tidak sedikit yang harus diselesaikan. Dengan kekuatannya, banyak mahasiswa wirausaha yang bisa menyeimbangkan antara prestasi dan bisnis.

Dengan menggunakan perspektif kekuatan, pekerja sosial dapat membantu individu agar individu tersebut tidak hanya fokus pada masalah. Perspektif ini tidak hanya melihat masalah sebagai fokus utama, melainkan melihat sumber-sumber yang tersedia di sekitar individu yang bisa dijadikan kekuatan untuk menggapai tujuan.

Perspektif berdasarkan kekuatan fokus pada membantu mengidentifikasi penggunaan dan peningkatan kekuatan dan sumber daya yang dimiliki oleh pribadi dan lingkungan. Kekuatan dapat bersumber dari mana saja. Seperti dapat bersumber dari dalam diri ataupun luar diri manusia tersebut. Kekuatan tersebut dapat dikembangkan agar mampu mencapai tujuan yang diinginkan.

Perspektif ini merupakan cara yang menarik untuk melihat seseorang dan keadaan mereka dengan pandangan yang positif dan optimis untuk menghadapi tantangan hidupnya. Apabila memandang sebuah masalah dengan optimis, akan merasa lebih mudah untuk menyelesaikan masalah yang ada. Manusia kadang tidak menyadari akan kemampuan yang dimilikinya. Tetapi pada dasarnya setiap manusia memiliki kemampuan untuk menyelesaikan tantangan atau masalah yang dimilikinya. Setiap manusia memiliki kekuatan dalam dirinya, dan kekuatan tersebut dapat digunakan untuk mengendalikan masalah yang mereka miliki.

Seperti yang telah dijelaskan perspektif kekuatan melihat kekuatan yang dimiliki klien. Peneliti tertarik untuk menjadikan mahasiswa yang berwirausaha sebagai objek penelitian. Berdasarkan penjelasan yang telah dikemukakan sebelumnya, pertanyaan yang hendak diungkap dalam penelitian ini adalah "Bagaimana kekuatan yang dimiliki oleh mahasiswa berwirausaha?"

\section{Metode, Hasil dan pembahasan}

Metode yang digunakan dalam penelitian ini yaitu metode deskriptif. Penelitian ini sering juga disebut penelitian noneksperimen karena tidak melakukan kontrol maupun manipulasi variabel penelitian. Metode deskriptif yakni suatu metode dalam penelitian yang bertujuan untuk memandu peneliti untuk mengeksplorasi dan atau memotret situasi sosial yang akan diteliti secara menyeluruh, luas dan mendalam (Sugiyono, 2008 : 209). Adapun tujuan dalam penelitian ini yaitu mengetahui gambaran kekuatan internal dan kekuatan eksternal yang dimiliki oleh mahasiswa berwirausaha.

Penelitian ini menggunakan pendekatan kualitatif dengan studi kasus mengenai kekuatan internal dan eksternal yang dimiliki oleh mahasiswa berwirausaha. Tujuannya yaitu untuk mengetahui faktorfaktor yang memberikan ciri khas pada tingkah laku. Tujuan berikutnya adalah memahami relasi antara lingkungan sosial dengan mahasiswa berwirausaha dan memahami 
kekuatan sebagai wujud dari relasi tersebut. Diharapkan dengan studi kasus, peneliti bisa mendapatkan gambaran lengkap berkaitan dengan kekuatan internal dan eksternal mahasiswa berwirausaha.

\section{Strength based perspective} merupakan dasar yang baik untuk praktek pekerjaan sosial, menurut Saleebey (1992) dalam Cowger (1994 : 263) berpendapat mengenai relevansi dari perspektif kekuatan merupakan "good basic social work practice". Perspektif kekuatan ini bersumber pada kekuatan dan kemampuan individu untuk mengatasi masalah, dan kesadaran dalam penggunaan kekuatan klien adalahbagian dari dasar teori dan praktek pekerjaan sosial.

Dikatakan sebagai dasar yang baik dalam praktek pekerjaan sosial dikarenakan strength based perspective membuat klien percaya bahwa dirinya memiliki kekuatan. Bahwa pada dasarnya tidak ada orang yang dilahirkan tanpa adanya kekuatan pada dirinya. Setiap manusia memiliki kekuatan pada dirinya.

Perpektif kekuatan memandang bahwa kekuatan yang dimiliki oleh setiap orang tersebut dapat membuatnya mampu mencapai tujuan yang ia miliki, ataupun ia mampu menyelesaikan masalah yang dimilikinya dengan menggunakan seluruh aset yang ada pada dalam atau luar dirinya. Seluruh sumber daya yang ada pada diri individu dapat dikembangkan agar dapat meningkatkan kepercayaan seseorang akan kemampuan yang ia miliki untuk mengatasi masalah yang terdapat pada dirinya.
Penelitian ini menggunakan setting mahasiswa yang berwirausaha. Dipilihnya setting tersebut ditujukan untuk mengetahui dan mendeskripsikan strength based assessment pada mahasiswa berwirausaha. Setting ini juga berperan sebagai informan.

Setiap orang memiliki kekuatan. Kemampuan dan kekuatan dalam mengatasi masalah diakui oleh perspektif kekuatan. Menurut NASW (2005) strength perspective adalah :

"The strength perspective recognizes an individual's strengths and abilities to cope with problems; and awareness and use of the client's strengths is part of foundation of social work theory and practice."

Strength based perspective menjadi salah satu dasar yang baik bagi praktik pekerja sosial. Seiring dengan pendapat Saleebey (1992) dalam Cowger (1994 : 263) terkait perspektif kekuatan "good basic social work practice". Hal ini membuat klien percaya bahwa ia memiliki kekuatan. Karena pada hakikatnya kekuatan dimiliki oleh setiap manusia. Saleebey (2000 : 127) mengungkapkan :

"The strengths approach obligates us to understand -to believe- that every body (no exceptions here) has exsternal and internal assets, competencies, and resources."

Memahami bahwa setiap orang memiliki aset eksternal dan internal, kompetensi dan sumberdaya menjadi bagian wajib dari perspektif kekuatan. Hal ini dapat dijadikan sebagai sumber kekuatan dalam penyelesaian masalah. Pengembangan aset bisa meningkatkan kepercayaan dan harapan 
klien. Seperti yang diungkapkan oleh Cowger (1994 : 265) :

"a strengths perspective of assessment provides structure and content for examination of realizable alternatives, for the mobilization of competencies that can make things different, and for the building of self confidence that stimulates hope."
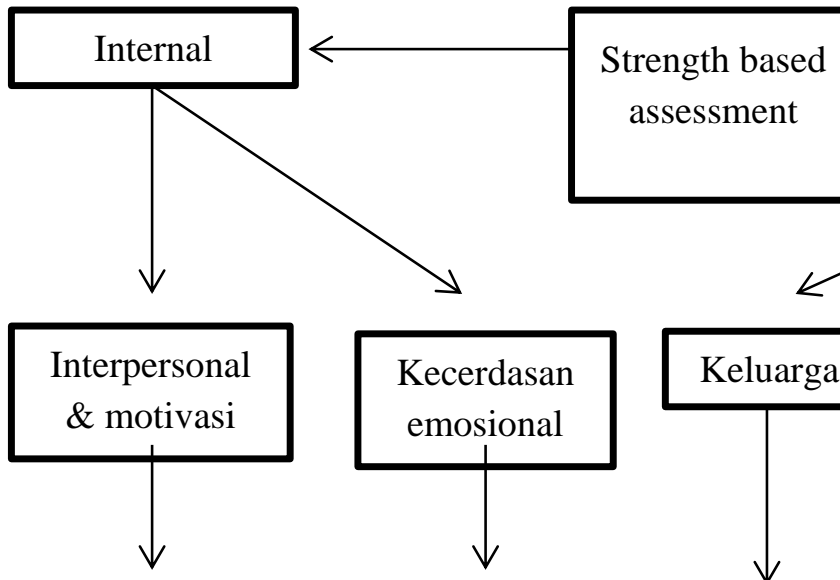

Keluarga

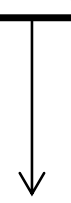

1) Introspeksi afirmatif

2) Mengatur diri sendiri dan

3) Merencanakan tujuan

4) Mengatur waktu

5) Meningkatkan kepercayaan diri

6) Motivasi diri

7) Mengembangk an dan mempertahank an sikap mental yang positif

Keterangan :

Pencapaian tujuan mahasiswa

1) Pemenuhan kebutuhan keakraban, kehangatan

2) Pemupukan rasa percaya diri dan perasaan aman utuk diri sendiri

3) Pemberian kesempatan untuk mengembangk an kemampuan

4) Menolong pencapaian tujuan
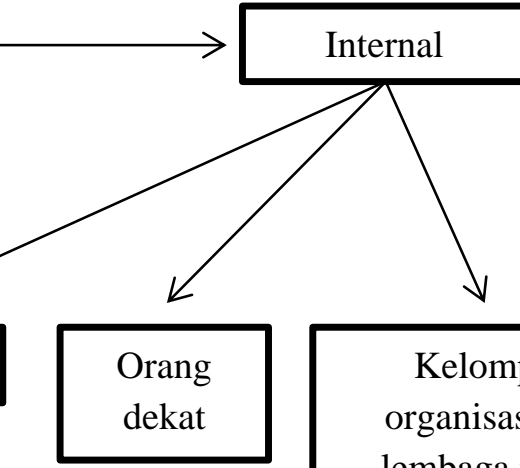

Kelompok, organisasi, dan lembaga publik

--------- = Fokus penelitian 


\begin{tabular}{|l|l|l|l|l|}
\hline Jurnal Penelitian \& PKM & Juli 2017 & Vol 4, No: 2 & Hal: $129-389$ & ISSN \\
\hline
\end{tabular}

Dalam praktik pekerjaan sosial terdapat proses assessment. Assessment merupakan proses kritis dalam praktik pekerjaan sosial (Raharjo, 2016). Diungkapkan dalam Hepworth and Larsen (1986) dalam Raharjo (2016 : 33) menjelaskan assessment sebagai berikut :

Assessmemt adalah proses pengumpulan, penganalisaan dan mesistesakan dan kedalam suatu formulasi yang menekankan dimensi vital sebagai berikut : 1 . Sifat permasalahan klien, termasuk perhatian khusus terhadap peran-peran yang klien dan hal penting lainnya yang sulit dijalankan; 2. Keberfungsian klien (kekuatan, keterbatasan, aset pribad dan kekurangan) serta hal penting lainnya; 3. Memotivasi klien untuk mengatasi masalah; 4. Relevansi faktor lingkungan yang turut mendukung timbulnya masalah; dan 5. Sumber-sumber yang tersedia atau dibutuhkan untuk mengurangi/menghilangkan kesulitan klien.

Perubahan dalam praktik pekerjaan sosial dari problem based assessment menjadi strength based assessment merupakan suatu kemajuan. Ketika pekerja sosial melakukan assessment dengan membahas kekurangan ataupun masalah dari klien, memungkinkan klien menjadi tidak percaya diri akan kemampuan dalam menyelesaikan masalahnya sendiri. Kekuatan yang sesungguhnya dimiliki oleh klien menjadi tidak tampak dan mungkin akan menyebabkan timbulnya masalah-masalah baru.

Beberapa kekurangan bisa terjadi dari kecenderungan pekerja sosial yang berfokus pada kelemahan. Kemungkinan klien tidak percaya diri menyelesaikan masalahnya apabila assessment dilakukan berbasis kekurangan. Masalah baru mungkin terjadi jika klien ditunjukan kekurangannya. Dijelaskan oleh Hepworth (2002) dalam Rankin (2006 : 10) :

"Point out that changes in practice have lagged far behind the change ini terms from diagnosis to assessment, for social workers persistence in formulating assessments that emphasize the pathology and dysfunction of clients - despite the time - honored social work platitude that social workers work with strengths and not with weakness."

Assessment kekuatan adalah cara baru dalam penyelesaian masalah. Dimana dalam menyelesaikan sesuatu masalah sekarang ini bukan hanya dengan mencari apa yang menjadi penyebab dari masalah tersebut, namun dapat dengan mencari kekuatan yang dapat membuat masalah tersebut diminimalisir. Dengan mencari kesalahan atau penyebab dari timbulnya suatu masalah tersebut dapat membuat seseorang menjadi fokus terhadap masalah yang terjadi pada dirinya tersebut dan melupakan kemampuannya bahwa sebenarnya ia mempunyai kekuatan untuk menyelesaikan masalahnya sendiri. Kekuatan tersebut dapat dikembangkan agar mampu mengurang timbulnua masalah yang ada. Serta mampu untuk membantu seseorang mencapai tujuannya.

Saleebey menyebutkan kekuatan internal yang dimiliki klien datang dari kemampuan interpersonal, motivasi, dan kekuatan emosional. Kekuatan internal tersebut berasal dari dalam diri klien. Kemampuan interpersonal ini adalah suatu keterampilan untuk mengenali dan merespon secara layak perasaan, sikap dan perilaku, motivasi serta keinginan orang lain serta bagaimana seseorang mampu membangun hubungan yang 
harmonis dengan memahami dan merespon orang lain. Hayes (1991:4) mengungkapkan :

"People will be motivated in ways that will bring about a desired state of affairs irrespective of whether they have acquired their repertoire of interpersonal skills and behavioral responses unconsciouslly, through experience, or via a deliberate and conscious process of self-development. On the other hand, somebody who attempts to satisfy her needs by consciously applying assertion skill that she has learned intentionally may also achieve her goals, but do so in a way that respects the right of others."

Jaringan keluarga, orang dekat, maupun organisasi yang mendukung dan memberikan klien kesempatan untuk bertindak merupakan beberapa sumber kekuatan eksternal. Semuanya berpotensi dalam penyediaan sumber daya yang dibutuhkan klien.

Ketika remaja, individu tertantang dan mengidentifikasikan dirinya pada tokoh yang idola. Orang tua sangat berpengaruh terhadap perkembangan seseorang. Pada masa awal individu akan mengidentifikasikan orang tuanya sebelum orang lain. Dengan demikian, keluarga berperan penting bagi perkembangan remaja.

Walaupun demikian, terdapat faktor lain yang mempengaruhi perkembangan anak seperti interaksi di dalam keluarga. Interaksi yang tidak baik akan berpengaruh buruk pada perkembangan. Bukan tidak mungkin konflik terjadi antara anak dan orang tuanya. Oleh karena itu diperlukan pengasuhan yang benar agar konflik dapat diminimalisir.

\section{Simpulan dan Saran}

Keberhasilan diperoleh tidak terlepas dari beberapa faktor. Semua orang memiliki kekuatan tetapi tidak semua orang menyadarinya. Padahal kekuatan yang ada bisa membantu dalam pencapaian tujuan. Lingkungan sosial pertama sebagai faktor eksternal yang berpengaruh besar dalam perkembangan adalah keluarga. Selain keluarga, orang terdekat bisa menjadi sumber kekuatan lain karena dukungan yang diberikan. Individu yang membutuhkan kesempatan dalam mengoptimalkan potensi dapat tersedia pada kelompok, organisasi, maupun lembaga publik.

Selain faktor eksternal, faktor internal juga mempengaruhi ketercapaian tujuan. Kemampuan interpersonal sebagai kemampuan mengarahkan perilaku menjadi bagian penting. Keinginan tidak boleh dilupakan karena tujuan tidak bisa tercapai bila tidak ada gambaran.Waktu harus dimanfaatkan agar sesuai perencanaan. Aspek motivasi dan kecerdasan mengatur emosi harus diperhatikan agar sikap dan mental positif dapat terjaga.

\section{Daftar Pustaka}

Cowger, Charles D. Assessing Client Strength : Clinical Assessment for Client Empowerment

National Association of Social Workers. 2005. NASW Standards for Social Work Practice in Health Settings.

Hayes, John. 2002. Interpersonal Skills Goalsdirected behaviour at work. USA : HapperCollin Academic

Raharjo, Santoso T. 2016. Asesmen \& Wawancara dalam Praktik Pekerjaan Sosial dan 


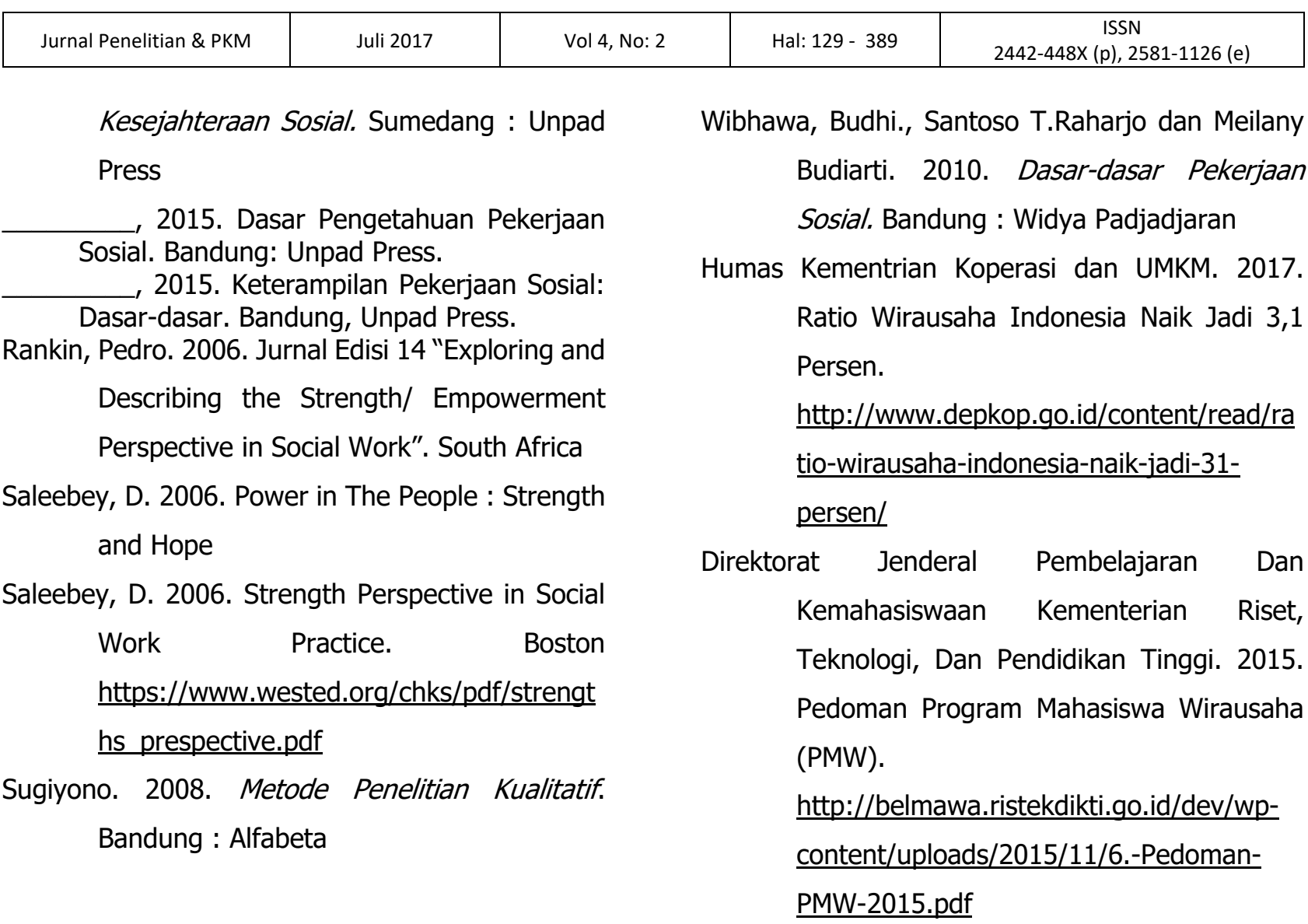

